\title{
Protective effect of histidine against iron-induced toxicity in HEK-293 cells
}

\author{
M. Vera-Aviles and G.O. Latunde-Dada \\ Division of Diabetes and Nutritional Sciences, King's College London, SE1 9NH, United Kingdom
}

Anaemia is a common complication of chronic kidney disease (CKD), and the prevalence increases with progression of kidney damage in the patients. Consequently anaemia in CKD is treated with iron supplementation of which excess iron has been associated with oxidative stress and tissue damage ${ }^{(1)}$. Iron has the capacity to accept and donate electrons readily, and this property allows redox reactivity and the generation of free radicals via Fenton and Haber-Weiss reactions ${ }^{(2)}$. Studies have reported that L-histidine exhibited antioxidant activities by scavenging free radicals and by chelating divalent metal ions ${ }^{(3)}$.

This study therefore evaluated the protective function of histidine in human embryonic kidney cells (HEK-293) that were challenged with a potent iron substrate. HEK-293 cells were treated with different concentrations of histidine before being subjected to $20 \mu \mathrm{mol} / \mathrm{L}$ of 8-hydroxyquinoline and $50 \mu \mathrm{mol} / \mathrm{L}$ of ferric ammonium citrate $(8 \mathrm{HQ}+\mathrm{FAC})$ for 2 hours. Afterwards cell viability was tested with 3-(4,5-dimethylthiazol-2yl)-2,5-diphenyltetrazolium bromide, (MTT assay). The effect of histidine on the levels of haemoxgenase-1 (HO-1) mRNA was measured by qPCR after cells were exposed to 8HQ + FAC for 6 hrs.

Histidine $(100-500 \mu \mathrm{M})$ significantly $\mathrm{P}<0.05)$ exerted a protective effect on HEK-293 cell viability against iron-induced stress. $\mathrm{N}$ - Acetylcysteine (NAC) at $500 \mu \mathrm{mol} / \mathrm{L}$, used as a positive control, was equally cytoprotective against iron-induced cell damage (Fig. 1). HO-1 mRNA increased significantly $(\mathrm{P}<0.05)$ when HEK-293 cells were pre-treated with NAC and then challenged with $8 \mathrm{HQ}+$ FAC (Fig 2). Pre-treatment with histidine only exhibited an insignificant increase in HO-1 mRNA level after exposure to $8 \mathrm{HQ}+$ FAC. HO-1 levels possibly correlate with antioxidant response to stress or oxidative damage in the cells.

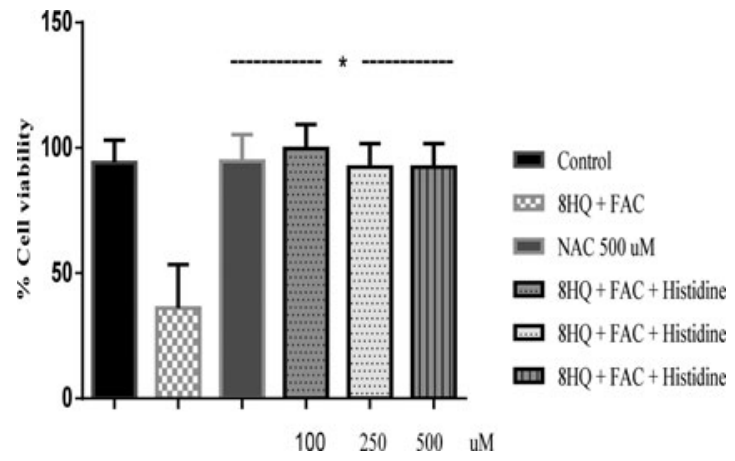

Fig. 1. Cytoprotective function of histidine

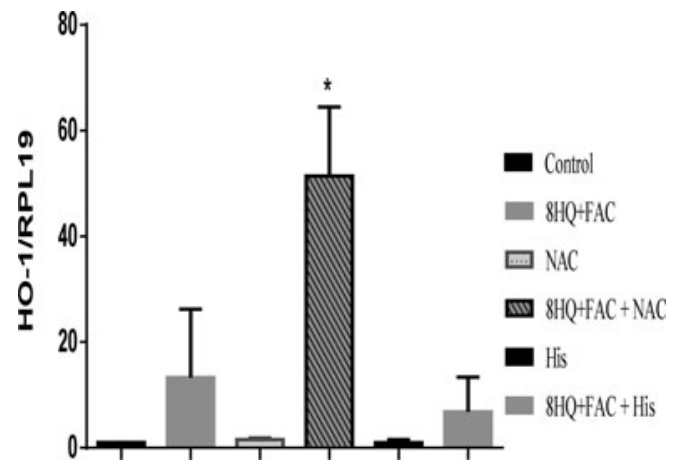

Fig. 2. HO-1 Expression

Histidine seems to protect HEK-293 cells against iron-induced cytotoxicity in a concentration dependent manner. The mechanisms by which histidine confers cytoprotection against iron damage are being investigated.

1. Macdougall I, (2007) Chronic Renal Failure 35, 457-60.

2. Del Vecchio L, Longhi S, Locatelli F (2016) Clinical Kidney Journal 9, 260-7.

3. Watanabe M, Suliman ME, Qureshi AR, et al. (2008) Am J Clin Nutr 87, 1860-6. 